\title{
Synthesis of a Novel Gemini Cationic Surfactant and Its Inhibition Behaviour and Mechanism Study on 2024 Al-Cu-Mg Alloy in Acid Solution
}

\author{
Juan Du (D), Qiaochu Chen (D), Qingmao Liu, and Xuelan Hu \\ Sino-European Institute of Aviation Engineering, Civil Aviation University of China, Tianjin, China \\ Correspondence should be addressed to Juan Du; dujuan247@163.com
}

Received 10 August 2017; Revised 31 December 2017; Accepted 22 January 2018; Published 1 March 2018

Academic Editor: Ramazan Solmaz

Copyright (C) 2018 Juan Du et al. This is an open access article distributed under the Creative Commons Attribution License, which permits unrestricted use, distribution, and reproduction in any medium, provided the original work is properly cited.

\begin{abstract}
Isopropylamine was taken as a raw material to synthesize a new multi-alkyl multiple quaternary-ammonium salts gemini surfactant bis[2-hydroxy-3-(dodecyldimethylammonio)propyl]-isopropylamine dichloride. The structure of the synthetic product was characterized by ${ }^{1} \mathrm{H}$ NMR and FTIR. The surface activity was investigated; the inhibition efficiencies and inhibition mechanism of the synthetic product were studied by weight loss method, electrochemical method, microscopic morphology observation, and adsorption model calculation. The results indicate that $\mathrm{cmc}$ of synthetic product was $9.204 \times 10^{-4} \mathrm{~mol} / \mathrm{L}$; when the concentrations were lower than $c m c$, the inhibition efficiencies rose substantially, which was up to $89.3 \%$ with the concentration of 9.204 $\times 10^{-4} \mathrm{~mol} / \mathrm{L}$; when they were higher than $\mathrm{cmc}$, inhibition efficiencies were basically unchanged; polarization tests showed that the synthesis product could restrain both anodic and cathodic reactions; when the concentrations were lower than $\mathrm{cmc}$, the adsorption of the synthetic product conformed to the Langmuir model, which formed monolayer on the $2024 \mathrm{Al}-\mathrm{Cu}-\mathrm{Mg}$ alloy surface; when they were higher than $\mathrm{cmc}$, it formed bilayer, so the adsorption of the synthetic product did not conform to the Langmuir model anymore.
\end{abstract}

\section{Introduction}

Aluminium and aluminium alloys have been widely used in aerospace, transportation, and construction industries because of their good mechanical properties, low density, and high corrosion resistance [1]. In the process of metal acid pickling, corrosion inhibitors are usually added to reduce the corrosion of acid to metallic matrix. During this process, surfactants are often selected as the corrosion inhibitors because of their good corrosion inhibition performance [25]. Unlike traditional surfactants, gemini surfactant has novel structure and excellent performance: using the spacer; it can connect two hydrophilic groups by chemical bonds to form a structure with double hydrophilic groups and double hydrophobic chains. This structure owns more advantages, such as higher surface tension, higher micelle forming ability, and better water solubility [6-8]. At present, gemini surfactant has been widely used in metal corrosion inhibition, transportation, medicine, and other industries, which plays a huge role in improving production process, enhancing product quality, reducing the cost, and increasing the added value [8-13]. Therefore, it is of great significance to study the synthesis process of gemini surfactant with novel structure and excellent properties and to apply it to pickling process of aluminium alloy for aviation.

In recent times, the studies of the corrosion inhibition performance of gemini surfactants are getting more and more; in particular, multiple quaternary-ammonium salts gemini surfactants have been reported [14-22]. Kim et al. [15] synthesized a series of new alkyl based quaternaryammonium cationic surfactants by inserting a methylimino group $\left(>\mathrm{NCH}_{3}\right)$, a dodecylimino group $\left(>\mathrm{NC}_{12} \mathrm{H}_{25}\right)$, a dimethylammonium group $\left(>\mathrm{N}^{+}\left(\mathrm{CH}_{3}\right)_{2}\right)$, and a dodecylmethylimmonio group $\left(>\mathrm{N}^{+}\left(\mathrm{CH}_{3}\right) \mathrm{C}_{12} \mathrm{H}_{25}\right)$ into two dodecyldimethyl quaternary-ammonium salts, respectively, and their properties were studied. The result showed that the multi-alkyl hydrophobic group was the main reason leading to the decrease of the critical micelle concentration; even 


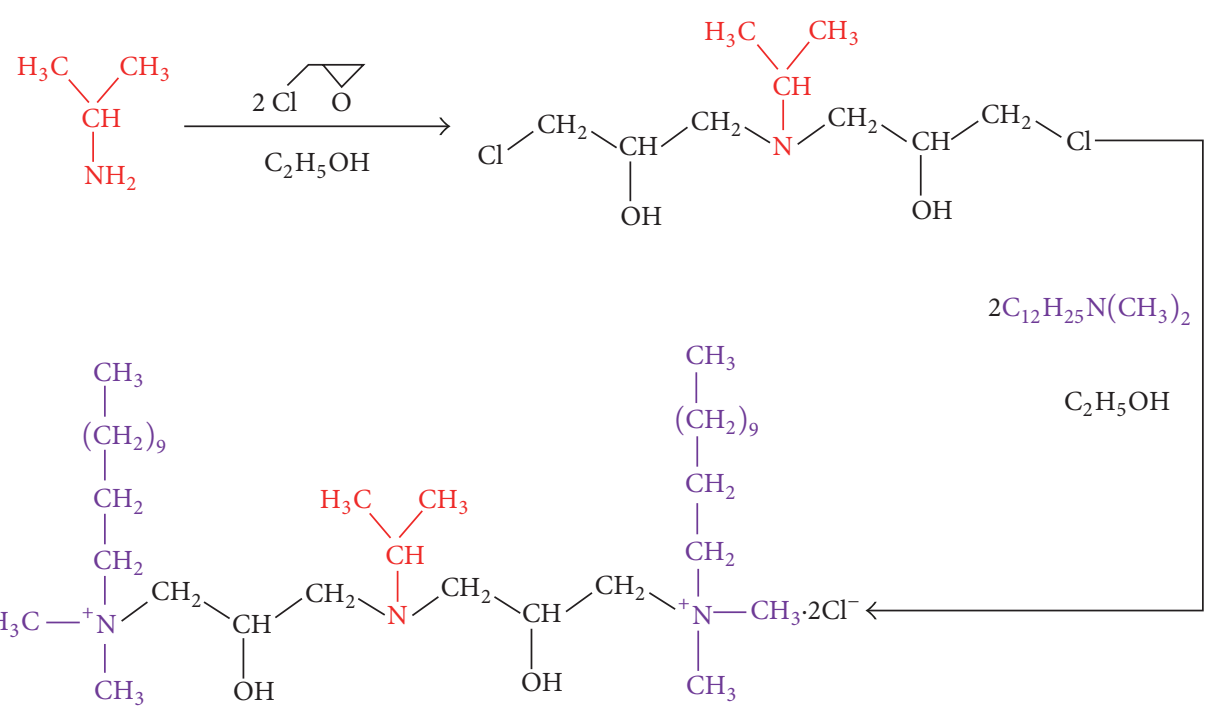

FIGURE 1: Synthetic route of bis[2-hydroxy-3-(dodecyldimethylammonio)propyl]-isopropylamine dichloride.

with long carbon chains, spacers did not play the role of hydrophobic groups. Lim et al. [17] synthesized single, double, triple quaternary-ammonium salts gemini surfactant by using condensation reactions. Surface tension test showed that the lowest surfactant tension was $28.88 \mathrm{mN} / \mathrm{m}$, which meant these gemini surfactants could be used to reduce the surface tension of the aqueous solution and to act as emulsifiers; foaming performance tests showed that the foam volume's decline rate increased when the number of ammonium and hydroxyl groups increased. In recent times, the studies of the corrosion inhibition performance of gemini surfactants are getting more and more [23-29]: Xu et al. [23] synthesized a new amide gemini inhibitor (OPDO) and studied its corrosion inhibition performance to Q235 carbon steel in hydrochloric acid solution. The results showed that OPDO had excellent corrosion inhibition effect for carbon steel, and it was a mixed inhibitor; its maximum inhibition rate was up to $99 \%$; the results also showed that the adsorption on the surface of carbon steel conformed to the Langmuir isothermal adsorption model. Hegazy et al. [24] synthesized three kinds of gemini surfactants with long chains containing benzene rings as spacers; results showed that, in acidic solution, those three kinds of surfactants could be used as mixed-type inhibitors with both physical and chemical adsorption models and its corrosion inhibition rate for carbon steel decreased firstly and then increased with temperature's increase.

The studies on corrosion inhibition performance for carbon steel are quite a lot now, while there are still few studies on corrosion inhibition performance of gemini surfactants for aviation used aluminium alloys; at the same time, the corrosion inhibition studies of multi-alkyl multiple quaternary-ammonium salts cationic gemini surfactants with imino groups as spacers are more focused on using straight chain imino groups as spacers, those using branched chain imino groups as spacers are rarely reported. In this paper, isopropylimino $\left(>\mathrm{NCH}\left(\mathrm{CH}_{3}\right)_{2}\right)$ is used as the spacer to connect two dodecyldimethyl quaternary-ammonium salts to finally synthesize a novel multi-alkyl bisquaternary ammonium cationic gemini surfactant; then its surface properties and its corrosion inhibition efficiency and the inhibition mechanism for aviation used Al-Cu-Mg 2024 alloy in $\mathrm{HCl}$ solution $(1 \mathrm{~mol} / \mathrm{L})$ are studied.

\section{Experimental}

\subsection{Reagents and Instruments}

Reagents. The reagents were isopropylamine, epichlorohydrin, dodecyldimethylamine, hexane, acetone, absolute ethanol, and hydrochloric acid (mass fraction: $36 \%-38 \%$ ). All the chemicals were of analytical reagent grade and were used without further purification.

Instruments. Bruker-400 NMR Spectrometer, BS 224S Electronic Analytical Balance (degree of accuracy: $\pm 0.1 \mathrm{mg}$ ), ParStat 2273 Electrochemical Workstation, HITACHI S-3400N Scanning Electron Microscope, 79-1 Magnetic Heating Stirrer, DSA25 Drop Shape Analyzer, Avatar 300 Fourier Infrared Spectrometric Analyzer, ZDHW Electric Heating Jacket, RE-25 Rotary Evaporator, iron stand, $150 \mathrm{~mL}$ roundbottom flask, Allihn condenser, separating funnel, $150 \mathrm{~mL}$ conical flask, and $250 \mathrm{~mL}$ beaker were used.

$\mathrm{Al}-\mathrm{Cu}-\mathrm{Mg}$ alloy for aviation with composition (in wt.\%) $\mathrm{Cu}$ 3.8-4.9, Mg 1.2-1.8, Mn 0.3-1.0, Cr 0.1, Zn 0.25, and Al (balance) was used as the subject investigated.

2.2. Synthesis of Bis[2-hydroxy-3-(dodecyldimethylammonio)propyl]-isopropylamine Dichloride. The preparation procedure of bis[2-hydroxy-3-(dodecyldimethylammonio)propyl]-lsopropylamine dichloride is shown as Figure 1:

Preparation of Middle Product. In a beaker of $250 \mathrm{ml}$, epichlorohydrin $(9.3 \mathrm{ml})$ was added at the speed of 10 seconds 
per drop to a mixture of absolute ethanol and isopropamide $(5 \mathrm{ml})$ under ice water bath. After that, the mixture was stirred at indoor temperature for $10 \mathrm{~h}$. Then, rotatory evaporator was used to remove solvent and redundant epichlorohydrin in the $40^{\circ} \mathrm{C}$ water bath for $1 \mathrm{~h}$ from which the transparent viscous liquid bis(2-hydroxy-3-chloropropyl) isopropylamine was obtained as the middle product.

Preparation of Final Product. The middle product (12.2 g), dodecyldimethylamine $(27 \mathrm{ml})$, and absolute ethanol were mixed and heated to reflux for $10 \mathrm{~h}$. From reduced pressure distillation at $60^{\circ} \mathrm{C}$ for $1 \mathrm{~h}$ and being washed three times by hexane, the white waxy product (32.6g) bis[2-hydroxy-3(dodecyldimethylammonio)propyl]-isopropylamine dichloride was finally extracted.

2.3. Surface Tension Measurement. At $25^{\circ} \mathrm{C}$, the DSA25 Drop Shape Analyzer was applied to measure surface tension curves of the mixed solution of $1 \mathrm{~mol} / \mathrm{L} \mathrm{HCl}$ and different concentrations of synthetic product. In addition, the critical micelle concentration $(\mathrm{cmc})$ and its corresponding surface tension can be ensured by the intersection point of the curves.

2.4. Weight Loss Measurement. The $2024 \mathrm{Al}-\mathrm{Cu}-\mathrm{Mg}$ alloy specimens were applied with dimensions $50 \mathrm{~mm} \times 25 \mathrm{~mm}$ $\times 2 \mathrm{~mm}$. The surface was abraded in sequence by abrasive papers ranging from $\# 800$ to \#2000 and then washed by deionized water, acetone, and absolute ethanol in order to remove the grease and impurities of the surface. Cold-blast air was used to dry the specimens and then initial weights of specimens were measured and recorded. After that, specimens were immersed in different corrosion solutions for $4 \mathrm{~h}$ and then a soft brush was dipped in acetone and absolute ethanol to remove the corrosion products on the metal surface. Finally the specimens were cleaned ultrasonically in deionized water and ultimate weights were measured and recorded again.

The average corrosion rate $(V)$ and the inhibition efficiency (IE, \%) the synthetic product were calculated as follows:

$$
\begin{gathered}
V=\frac{m_{0}-m}{S \times t}, \\
\operatorname{IE~}(\%)=\frac{V_{0}-V}{V_{0}} \times 100,
\end{gathered}
$$

where $m_{0}$ and $m_{1}$ are, respectively, the initial and ultimate weight; $S$ is the immersed surface; $t$ is the corrosion duration; $V$ and $V_{0}$ are, respectively, the average corrosion rate in presence and absence on synthetic product.

2.5. Electrochemical Measurement. Electrochemical measurement was carried out by using ParStat 2273 Electrochemical workstation at room temperature $25^{\circ} \mathrm{C}$. In the threeelectrode assembly, $2024 \mathrm{Al}-\mathrm{Cu}-\mathrm{Mg}$ alloy work electrode with working surface $1 \mathrm{~cm}^{2}$, Pt wire auxiliary electrode with area $3 \mathrm{~cm}^{2}$, and $\mathrm{Ag} / \mathrm{AgCl}$ reference electrode filled with saturated $\mathrm{KCl}$ solution ( $0.1981 \mathrm{~V}$ versus NHE) were used. Among them, the distance between work electrode and auxiliary electrode

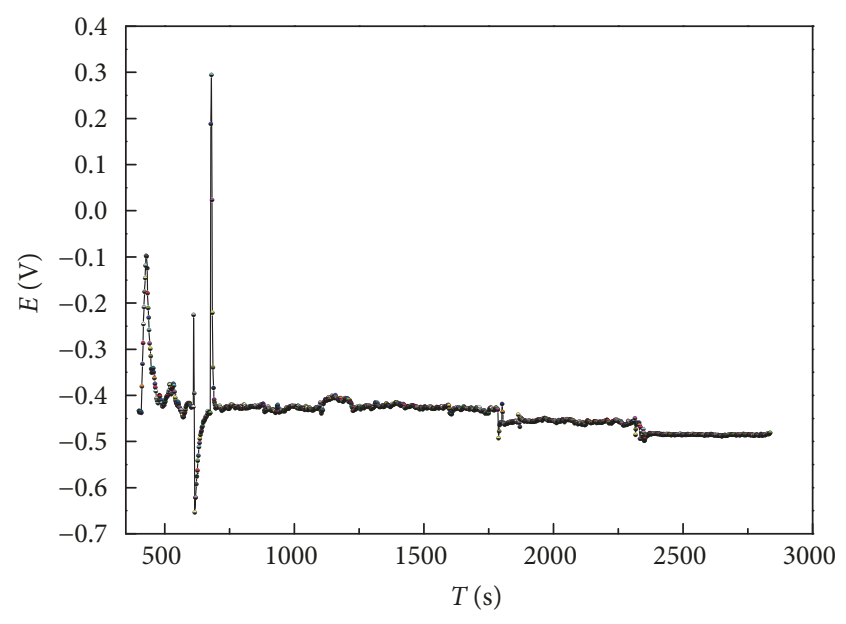

FIGURE 2: OCP test result.

was about $12 \mathrm{~cm}$, and the distance between work electrode and reference electrode was about $2 \mathrm{~cm}$.

Before the impedance test, open circuit potential (OCP) test was carried out to ensure that the follow-up experiments were tested in a stable state. The OCP plot of $2024 \mathrm{Al}-\mathrm{Cu}-\mathrm{Mg}$ alloy in $1 \mathrm{~mol} / \mathrm{L} \mathrm{HCl}$ solution with $9 \times 10^{-4} \mathrm{~mol} / \mathrm{L}$ synthetic product was shown in Figure 2.

It can be seen that, after soaking for about 15 minutes, the curve reaches a stable stage, and the OCP is basically stable at $-0.48 \mathrm{~V}$. Therefore, impedance tests were carried out after 15 minutes of immersion in the specimens. The results obtained by adding other concentrations of the synthetic product are basically the same.

In order to make an approximate equilibrium of the system, potentiodynamic polarization curves were measured under scanning range of $\pm 250 \mathrm{mV}$ relative to the OCP, and scanning rate of $0.166 \mathrm{mV} / \mathrm{s}$. The following equation was used to compute the inhibition efficiency as

$$
\operatorname{IE}(\%)=\frac{I_{0}-I}{I_{0}} \times 100,
$$

where $I_{0}$ and $I$ are, respectively, the corrosion current intensity in absence and presence of synthetic product.

The impedance measurements were carried out under frequency range of $10 \mathrm{mHz} 100 \mathrm{kHz}$ and amplitude of $10 \mathrm{mV}$. Equivalent circuits were simulated from ZsimpWin software. The inhibition efficiency of synthetic product was calculated as follows:

$$
\operatorname{IE}(\%)=\frac{R_{p}-R_{p}^{\prime}}{R_{p}} \times 100,
$$

where $R_{p}^{\prime}$ and $R_{p}$ are, respectively, the polarization resistance in absence and presence of synthetic product.

2.6. Corrosion Surface Observation. HITACHI S-3400N scanning electronic microscope (SEM) was applied to observe the corrode surface in absence and presence of synthetic product in order to determine their corrosion state and degree. 
2.7. Adsorption Isothermal Model. The adsorption mechanism of inhibitor can be justified by the adsorption isothermal model where a classic Langmuir adsorption model obeys the following assumption: every adsorption site on the metal surface shares the same properties and can only adsorb one molecule at best, the molecules onside exert no acting force on each other. The adsorption isothermal formula is

$$
\frac{C}{\theta}=C+\frac{1}{K}
$$

where $C$ is the concentration of inhibitor; $K$ is the adsorption equilibrium constant; $\theta$ is the fraction of coverage which can be attained from

$$
\theta=\frac{\mathrm{IE}}{\mathrm{IE}_{m}},
$$

where IE is the inhibition efficiency of corresponding inhibitor concentration; $\mathrm{IE}_{m}$ is the maximum inhibition efficiency. Besides, the Langmuir model can be also presented as follows [30]:

$$
\frac{1}{V}=K^{\prime \prime}+K^{\prime} C
$$

where $V$ is the corrosion rate; $K^{\prime \prime}$ is the reciprocal of the uninhibited corrosion rate; $K^{\prime}$ is a constant, which resulted from the weight loss method.

2.8. Adsorption Thermodynamics Parameters. The adsorption equilibrium constant $K$ could be concluded from Langmuir simulated curve. The relation between $K$ and the adsorption free energy $\Delta G_{\text {ads }}^{0}$ can be expressed as

$$
K=\left(\frac{1}{55.5}\right) \exp \frac{-\Delta G_{\mathrm{ads}}^{0}}{R T},
$$

where $R$ is molar gas constant, $8.314 \mathrm{~J} \cdot \mathrm{mol}^{-1} \cdot \mathrm{K}^{-1} ; T$ is the environmental temperature, $298 \mathrm{~K} ; \Delta G_{\text {ads }}^{0}$ is used to justify furthermore the adsorption mechanism.

2.9. FTIR Tests. The absorption peaks in FTIR curves can be used to determine whether a new chemical bond occurs or disappears on the metal surface. FTIR curves of corrosion products on the surface of $2024 \mathrm{Al}-\mathrm{Cu}-\mathrm{Mg}$ alloy in $1 \mathrm{~mol} / \mathrm{L}$ $\mathrm{HCl}$ solution with/without the synthetic product have been plotted to determine the adsorption type of the synthetic product.

\section{Results and Discussion}

3.1. Structure Characterization of Bis[2-hydroxy-3-(dodecyldimethylammonio)propyl]-isopropylamine Dichloride. The FTIR test result is shown in Figure 3. It can be seen that $3371 \mathrm{~cm}^{-1}$ is the vibration peak of $-\mathrm{OH}$; the two adsorption peaks at $2923 \mathrm{~cm}^{-1}$ and $2853 \mathrm{~cm}^{-1}$ are characteristic vibration peaks of long carbon chains [31]; $1462 \mathrm{~cm}^{-1}$ is the flexural vibration peak of C-H [32]; peaks between $1050 \sim 1200 \mathrm{~cm}^{-1}$ and $500 \sim 700 \mathrm{~cm}^{-1}$ are the characteristic peaks of C-C, C-N,

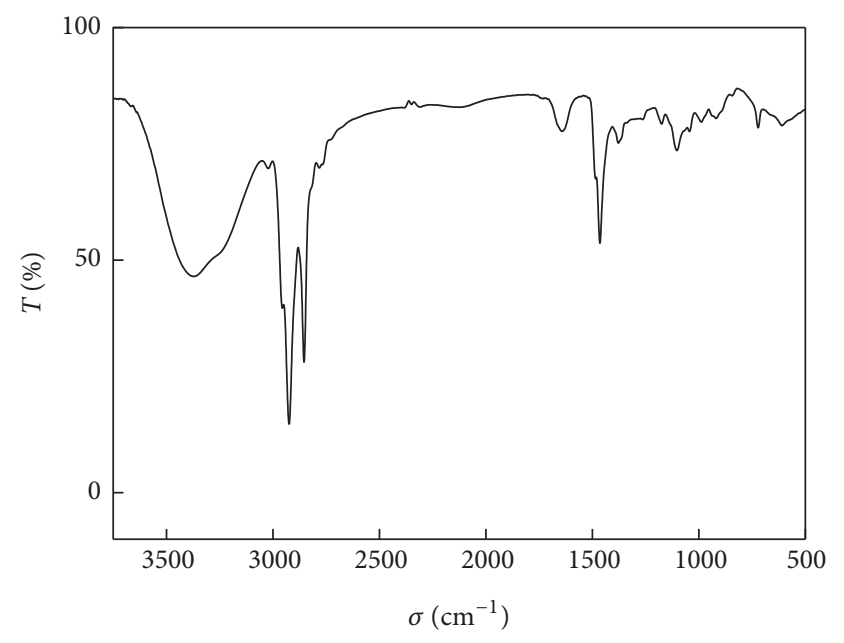

FIGURE 3: Infrared spectra of synthetic product.

and $\mathrm{C}-\mathrm{Cl}$ [32]. Based on the analysis, it can be concluded that the synthetic product is the target product.

${ }^{1} \mathrm{H}$ NMR test result of the synthetic product is shown in Figure 4. Specific analysis is as follows: ${ }^{1} \mathrm{H} \mathrm{NMR}\left(\mathrm{CDCl}_{3}\right)$ $\delta$ 0.806-0.840 (t, 6H, $\left.\left(\mathrm{CH}_{3}\right)_{2}\right), 1.017-1.033(\mathrm{~m}, 6 \mathrm{H}$, $\left.\mathrm{CH}_{3}(\mathrm{CH}) \mathrm{CH}_{3}\right), \quad 1.200-1.289\left(\mathrm{~m}, 36 \mathrm{H}, \quad\left(\mathrm{CH}_{3}\left(\mathrm{CH}_{2}\right)_{9}\right)_{2}\right)$, $1.687\left(\mathrm{~s}, \quad 4 \mathrm{H}, \quad\left(\mathrm{CH}_{3}\left(\mathrm{CH}_{2}\right)_{9} \mathrm{CH}_{2}\right)_{2}\right), 2.686-2.745 \quad(\mathrm{~m}$, $\left.1 \mathrm{H}, \mathrm{CH}_{3}(\mathrm{CH}) \mathrm{CH}_{3}\right), 2.956-3.056\left(\mathrm{~m}, 4 \mathrm{H},\left(\mathrm{CH}_{2} \mathrm{CH}\right)_{2}\right)$, 3.252-3.312 (m, 12H, $\left.\left(\mathrm{N}^{+}\left(\mathrm{CH}_{3}\right)_{2}\right)_{2}\right), 3.542-3.554(m, 8 \mathrm{H}$, $\left.\left(\mathrm{N}^{+}\left(\mathrm{CH}_{2}\right)_{2}\right)_{2}\right), 3.870-3.901\left(\mathrm{~m}, 2 \mathrm{H},\left(\mathrm{CH}_{2} \mathrm{CH}\right)_{2}\right), 4.293-4.309$ $\left(\mathrm{m}, 2 \mathrm{H},(\mathrm{OH})_{2}\right)$. By analyzing the peak positions of relative hydrogen atoms and the relative areas of absorption peaks, it can be concluded again that the synthetic product is the target product.

3.2. Surface Tension Test. Surface tension $(\gamma)$ was plotted versus the logarithm of concentration of synthetic product, as shown in Figure 5. As seen in Figure 5, at low concentrations, $\gamma$ drops sharply with the increase of $\log C$; while, at higher concentrations, $\gamma$ keeps essentially constant. The surface tensions of these two states are fitted linearly, respectively, and the intersection point is approximately the critical micelle concentration $(\mathrm{cmc})$ of the synthetic product [33]. Thus it can be seen that the $c m c$ of the synthetic product is 9.204 $\times 10^{-4} \mathrm{~mol} / \mathrm{L}$, which is $1 \sim 2$ orders of magnitude lower than that of conventional single-chain quaternary-ammonium salt surfactant. cmc of a range of conventional and gemini surfactants are given in Table 1.

The cause of the decrease of $c m c$ may be that the synthetic product connects two long carbon chains replacedammonium cations by using its spacer group, thus greatly increases the number of carbon atoms of the hydrophobic group [15], and finally reduces the $c m c$. Meanwhile, the hydrophilic group is connected with the spacer group by a chemical bond, thus could arrange closely in adsorption layer of the solution surface, and the hydrophobic groups arrange vertically in solid-liquid interface, thereby, the surface activity is increased and it is easier to form micelles. 


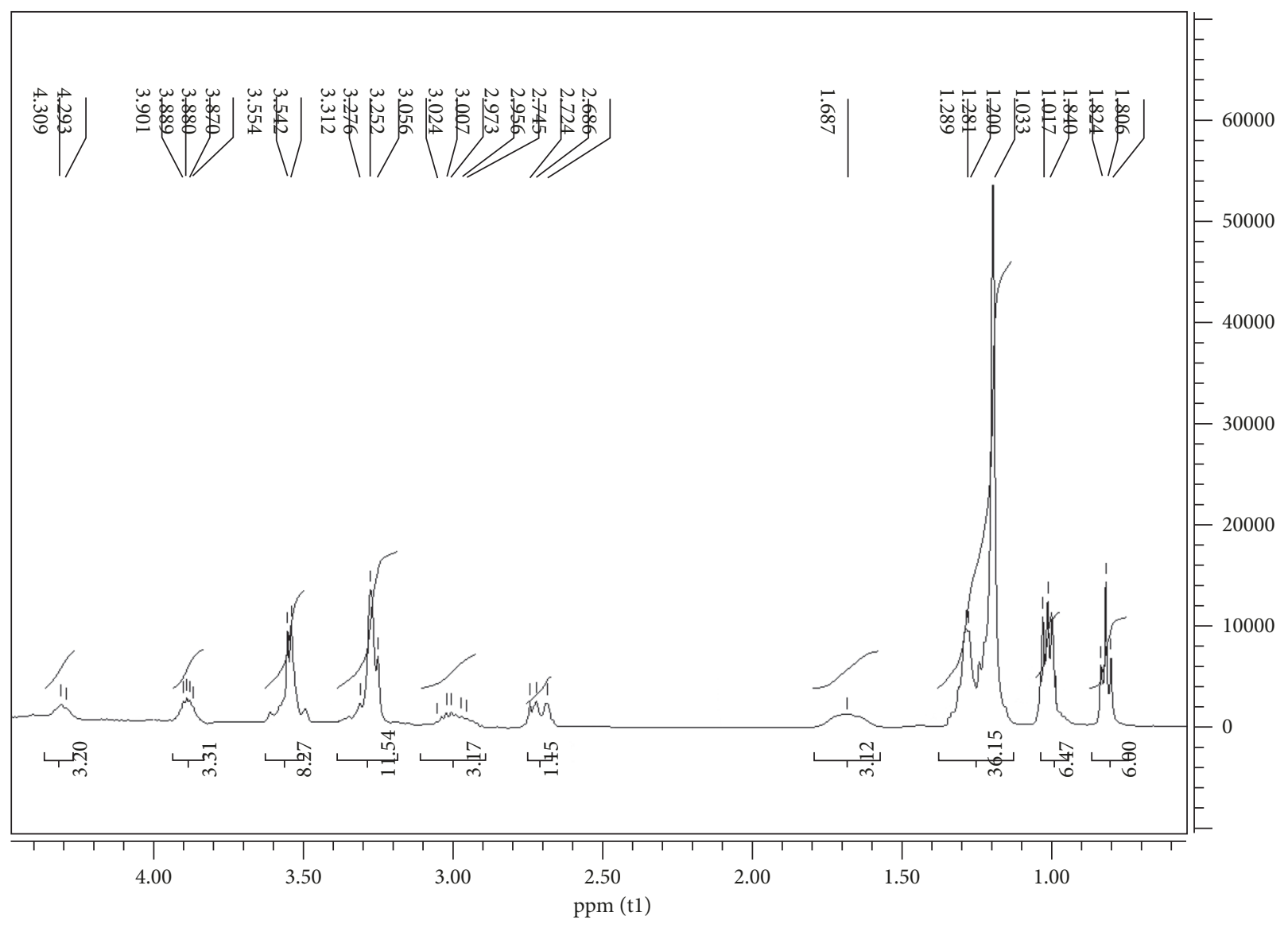

FIgURE $4:{ }^{1} \mathrm{H}$ NMR spectra of synthetic product.

TABLE 1: $\mathrm{cmc}$ of conventional and gemini surfactants.

\begin{tabular}{lcc}
\hline Surfactants & $c m c /$ mmol $\cdot \mathrm{L}^{-1}$ & References \\
\hline $\mathrm{C}_{12} \mathrm{H}_{25} \mathrm{~N}^{+}\left(\mathrm{CH}_{3}\right)_{3} \mathrm{Cl}^{-}$ & 22 & {$[34]$} \\
$\mathrm{C}_{12} \mathrm{H}_{25} \mathrm{~N}^{+}\left(\mathrm{CH}_{3}\right)_{3} \mathrm{Br}^{-}$ & 16 & {$[34]$} \\
$\mathrm{C}_{4} \mathrm{H}_{8}\left(\mathrm{C}_{12} \mathrm{H}_{25} \mathrm{~N}^{+} \mathrm{Me}_{2} \mathrm{Br}^{-}\right)_{2}$ & 1.09 & 1.01 \\
$\mathrm{C}_{6} \mathrm{H}_{12}\left(\mathrm{C}_{12} \mathrm{H}_{25} \mathrm{~N}^{+} \mathrm{Me}_{2} \mathrm{Br}^{-}\right)_{2}$ & 0.99 \\
$\mathrm{C}_{12} \mathrm{H}_{25} \mathrm{~N}^{+}\left(\mathrm{CH}_{3}\right)_{2}-\mathrm{CH}_{2}-\mathrm{CH}(\mathrm{OH})-\mathrm{CH}_{2}-\mathrm{N}\left(\mathrm{CH}_{3}\right)-\mathrm{CH}_{2}-\mathrm{CH}(\mathrm{OH})-\mathrm{CH}_{2}-(\mathrm{CH})_{2} \mathrm{~N}^{+} \mathrm{C}_{12} \mathrm{H}_{25} 2 \mathrm{Cl}^{-}$ & {$[35]$} \\
$\mathrm{C}_{12} \mathrm{H}_{25} \mathrm{~N}^{+}\left(\mathrm{CH}_{3}\right)_{2}-\mathrm{CH}_{2}-\mathrm{CH}(\mathrm{OH})-\mathrm{CH}_{2}-\mathrm{N}\left(\mathrm{CH}\left(\mathrm{CH}_{3}\right)_{2}\right)-\mathrm{CH}_{2}-\mathrm{CH}(\mathrm{OH})-\mathrm{CH}_{2}-(\mathrm{CH} 3)_{2} \mathrm{~N}^{+} \mathrm{C}_{12} \mathrm{H}_{25}$ & 0.92 \\
$2 \mathrm{Cl}^{-}($synthetic product$)$ & {$[15]$} \\
$\mathrm{C}_{12} \mathrm{H}_{25} \mathrm{~N}^{+}\left(\mathrm{CH}_{3}\right)_{2}-\mathrm{CH}_{2}-\mathrm{CH}(\mathrm{OH})-\mathrm{CH}_{2}-\mathrm{N}\left(\mathrm{C}_{12} \mathrm{H}_{25}\right)-\mathrm{CH}_{2}-\mathrm{CH}(\mathrm{OH})-\mathrm{CH}_{2}-(\mathrm{CH} 3)_{2} \mathrm{~N}^{+} \mathrm{C}_{12} \mathrm{H}_{25} 2 \mathrm{Cl}^{-}$ & 0.0062 \\
\hline
\end{tabular}

\subsection{Inhibition Properties of Bis[2-hydroxy-3-(dodecyldimeth- ylammonio)propyl]-isopropylamine Dichloride}

3.3.1. Weight Loss Test. The influence of the concentration of synthetic product on corrosion rate $(V)$ and inhibition efficiency (IE) of $2024 \mathrm{Al}-\mathrm{Cu}-\mathrm{Mg}$ alloy in $1 \mathrm{~mol} / \mathrm{L} \mathrm{HCl}$ solution has been studied by static weight loss method, as shown in Figure 6. It can be seen that with the concentration increasing from $5 \times 10^{-5} \mathrm{~mol} / \mathrm{L}$ to $9 \times 10^{-4} \mathrm{~mol} / \mathrm{L}, V$ decreases from $7.2401 \times 10^{-5} \mathrm{~g} \cdot \mathrm{mm}^{-2} \cdot \mathrm{h}^{-1}$ to $1.3759 \times 10^{-5} \mathrm{~g} \cdot \mathrm{mm}^{-2} \cdot \mathrm{h}^{-1}$, while IE is doubled from $43.5 \%$ to $89.3 \%$. However, with the concentration increasing from $9 \times 10^{-4} \mathrm{~mol} / \mathrm{L}$ to $2.4 \times 10^{-3} \mathrm{~mol} / \mathrm{L}, V$ declines slightly from $1.3759 \times 10^{-5} \mathrm{~g} \cdot \mathrm{mm}^{-2} \cdot \mathrm{h}^{-1}$ to $1.0123 \times$ $10^{-5} \mathrm{~g} \bullet \mathrm{mm}^{-2} \cdot \mathrm{h}^{-1}$; similarly, IE increases slightly from $89.3 \%$ to $92.1 \%$.

Combined with surface tension test result, it can be analyzed that corrosion rate first decreases rapidly with the increase of the concentration of synthetic product; when the concentration is near to $c m c\left(9.204 \times 10^{-4} \mathrm{~mol} / \mathrm{L}\right)$, the corrosion rate decreases from a rapid decline to a slow decline, and eventually almost no change occurs; the rule of inhibition efficiency is just the opposite. The reason may be that when the concentration is low, the ammonium cation of the synthetic product is easy to be adsorbed to 


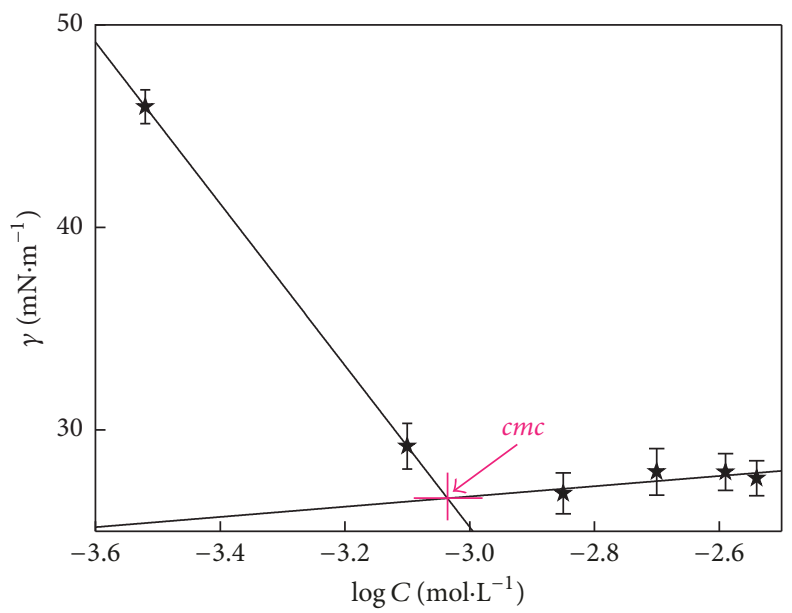

FIGURE 5: Surface tension $(\gamma)$-logarithm of concentration $(\log C)$ curve of synthetic product.

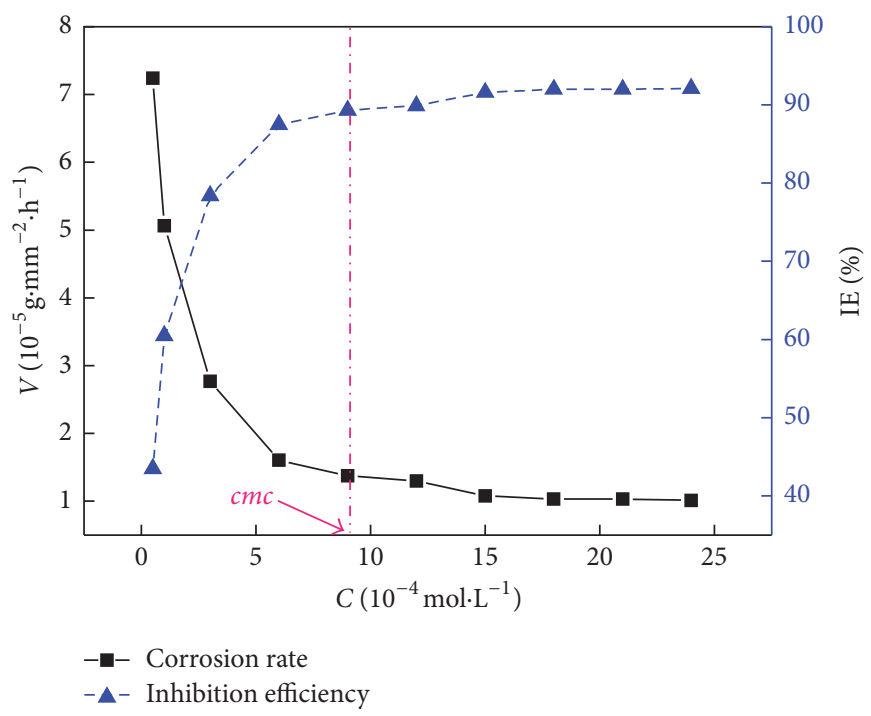

FIGURE 6: Static weight loss curve of $2024 \mathrm{Al}-\mathrm{Cu}-\mathrm{Mg}$ alloy in $1 \mathrm{~mol} / \mathrm{L} \mathrm{HCl}$ solution with different concentrations of synthetic product.

the surface of $2024 \mathrm{Al}-\mathrm{Cu}-\mathrm{Mg}$ alloy; at the same time, the long carbon chains arrange orientated and orderly, which form a protective film on the surface of the alloy and play a role in corrosion inhibition; when the concentration reaches to $c m c$, the adsorption of the surfactant molecules on the metal surface is approximately saturated; therefore, with the increase of concentration, the corrosion rate and corrosion efficiency change slowly or almost remain unchanged.

3.3.2. Potentiodynamic Polarization Measurements. Figure 7 represents the cathodic and anodic curves measured by adding different concentrations of synthetic product $(0.5 \sim 9 \times$ $10^{-4} \mathrm{~mol} / \mathrm{L}$ ) into $1 \mathrm{~mol} / \mathrm{L} \mathrm{HCl}$; related parameters of polarization measurements are shown in Table 2. It could be observed that $I_{\text {corr }}$ decreases with the increase of synthetic product's concentration. When the concentration is $9 \times 10^{-4} \mathrm{~mol} / \mathrm{L}, I_{\text {corr }}$ has reduced by an order of magnitude over the blank solution and reaches $7.07 \times 10^{-4} \mathrm{~A}$. Meanwhile, both cathodic and anodic curves move in the direction of decreasing the current density; $E_{\text {corr }}$ changes little compared with blank solution; it suggests that both cathodic and anodic reactions are suppressed with the addition of synthetic product, besides; the synthetic product is a mixed-type inhibitor which reduces anodic dissolution and also retards the hydrogen evolution reaction. The corrosion efficiencies (IE) are calculated by using (2); results show that IE increases monotonously with the increase of synthetic product and is up to $88.6 \%$, which means the synthetic product has a good inhibiting effect on metal corrosion. This result is consistent with the weight loss method.

3.3.3. Electrochemical Impedance Spectroscopy. Nyquist plots of $2024 \mathrm{Al}-\mathrm{Cu}-\mathrm{Mg}$ alloy in absence and presence of different concentrations of the synthetic product are shown in Figure 8. The inspection of Figure 8 reveals that all the Nyquist plots are composed of capacitive arcs in the high 


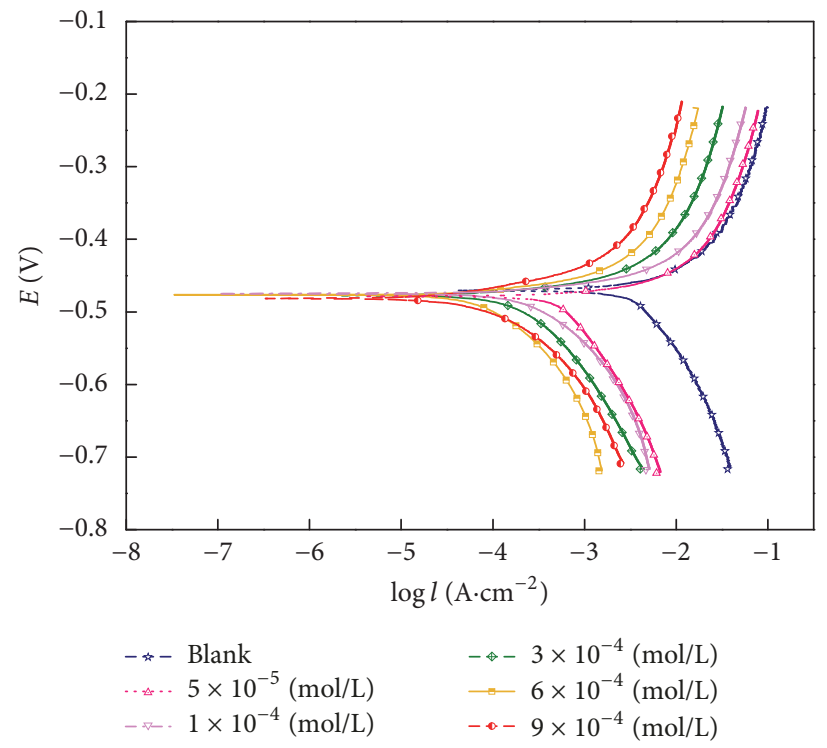

FIGURE 7: Tafel polarization curves with different concentrations of synthetic product added.

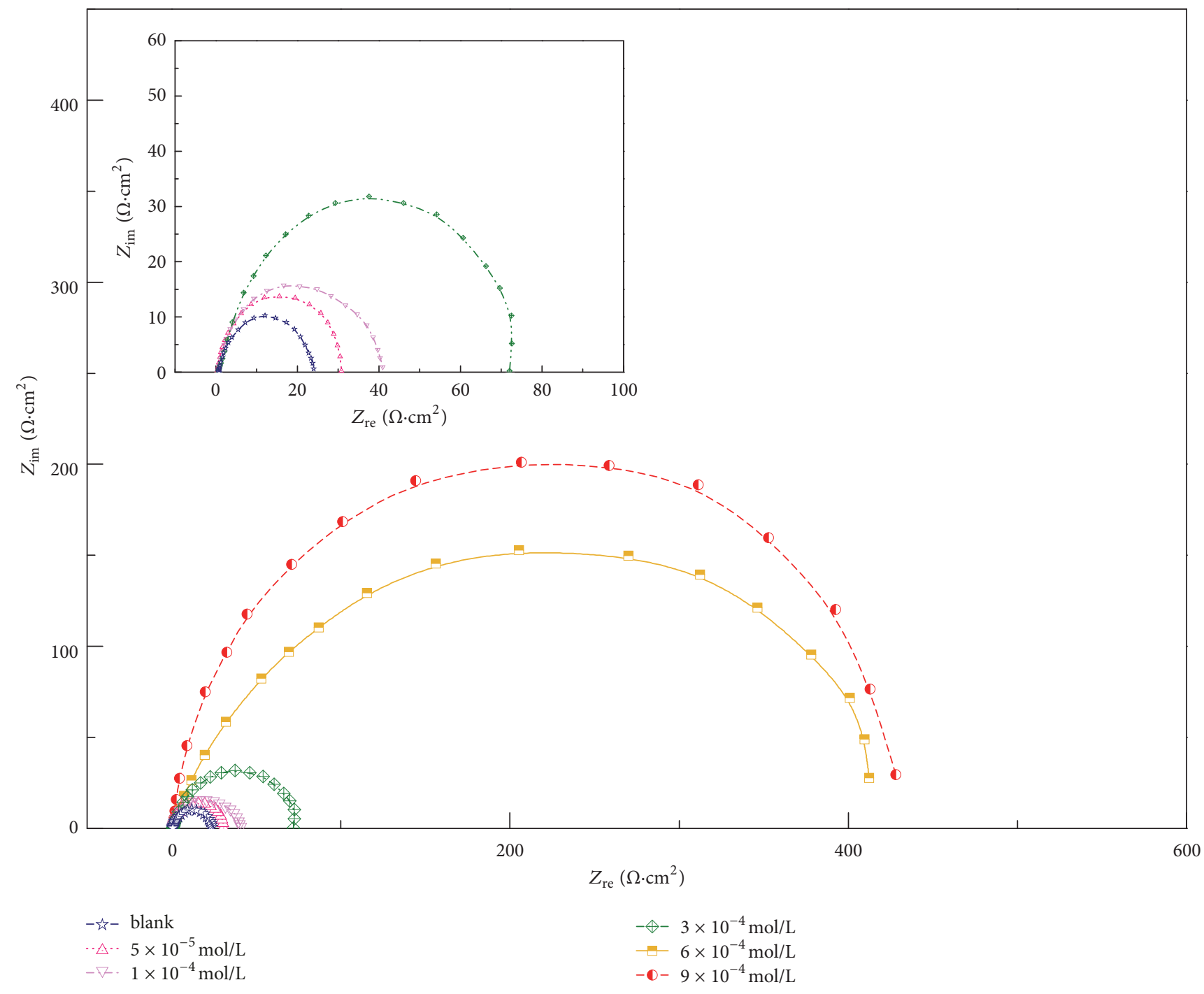

FIGURE 8: Nyquist diagrams with different concentrations of synthetic product added. 


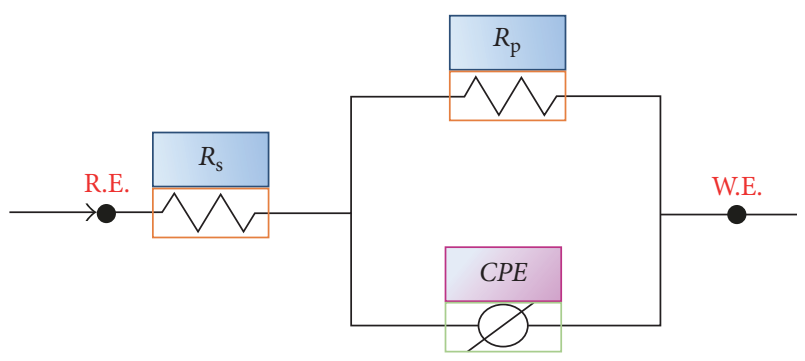

FIGURE 9: Equivalent circuit of Nyquist diagrams.

TABLE 2: Test parameters obtained from Tafel polarization curves.

\begin{tabular}{lccc}
\hline$C / 10^{-4} \mathrm{~mol} \cdot \mathrm{L}^{-1}$ & $I_{\text {corr }} / 10^{-3} \mathrm{~A}$ & $E_{\text {corr }} / \mathrm{V}$ & $\mathrm{IE} / \%$ \\
\hline 0 & 6.198 & -0.470 & $/$ \\
0.5 & 3.564 & -0.479 & 42.5 \\
1 & 2.386 & -0.475 & 61.5 \\
3 & 1.382 & -0.477 & 77.7 \\
6 & 1.004 & -0.476 & 83.8 \\
9 & 0.707 & -0.481 & 88.6 \\
\hline
\end{tabular}

Note. C: concentration of synthetic product; $I_{\text {corr }}$ : corrosion current; $E_{\text {corr }}$ : corrosion potential; IE: inhibition efficiency.

frequency zone, which are related to double-layer capacitance as well as the charge transfer resistance. The capacitive arcs are depressed in nature; it is due to the micro roughness of the surface of metal formed during corrosion.

The proposed equivalent circuit by ZsimpWin software is shown in Figure 9; related parameters are listed in Table 3. It can be analyzed that $R_{p}$ increases and $Y_{0}$ decreases with increasing in the concentration of the synthetic product, which indicates the formation of adsorption layer on the surface of the alloy. It can be calculated through (3) that the inhibition efficiency increases with increasing in the concentration of the synthetic product and is up to $94.6 \%$ at 9 $\times 10^{-4} \mathrm{~mol} / \mathrm{L}$. Compared with the weight loss test results, the inhibition efficiencies obtained by impedance test are slightly higher, but the overall trend is the same, so the results are still consistent.

3.3.4. Surface Topography Analysis. Figure 10 demonstrates the damage caused by exposure of $2024 \mathrm{Al}-\mathrm{Cu}-\mathrm{Mg}$ alloy to $1 \mathrm{~mol} / \mathrm{L} \mathrm{HCl}$ in absence and presence of the synthetic product for 4 hours. It is evident that the surface becomes very rough and a large amount of corrosion pits can be found after being corroded in $1 \mathrm{~mol} / \mathrm{L} \mathrm{HCl}$ without any synthetic product, which means that a severe corrosion has happened; when the synthetic product is added, the surface becomes smoother and no big corrosion pits could be found. Figure 10(b) clearly shows that the synthetic product could form a smooth adsorption layer on the surface to inhibit the corrosion of $2024 \mathrm{Al}-\mathrm{Cu}-\mathrm{Mg}$ alloy.

3.3.5. Adsorption Isotherms and Thermodynamic Calculations. Figure 11 shows the adsorption isotherms of the synthetic product on $\mathrm{Al}-\mathrm{Cu}-\mathrm{Mg}$ alloy in $1 \mathrm{~mol} / \mathrm{L} \mathrm{HCl}$ solution. In

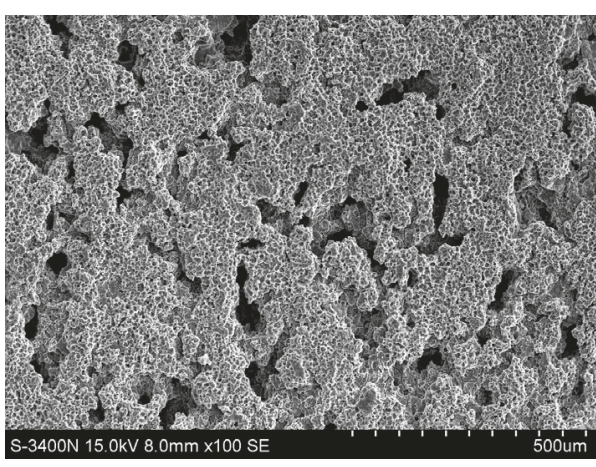

(a)

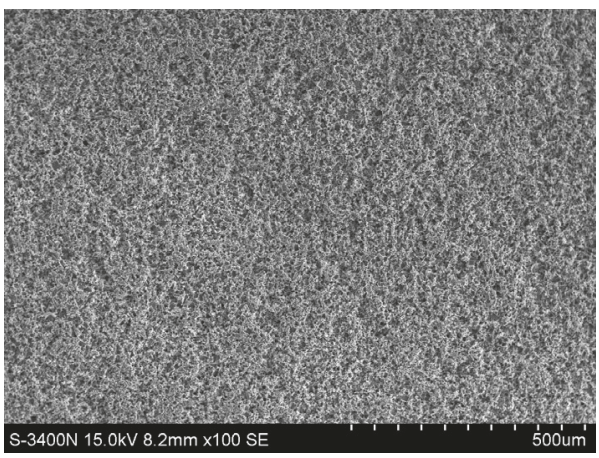

(b)

FIGURE 10: Corrosion surface morphology of $2024 \mathrm{Al}-\mathrm{Cu}-\mathrm{Mg}$ alloy: (a) $1 \mathrm{~mol} / \mathrm{L} \mathrm{HCl}$; (b) $1 \mathrm{~mol} / \mathrm{L} \mathrm{HCl}+$ synthetic product.

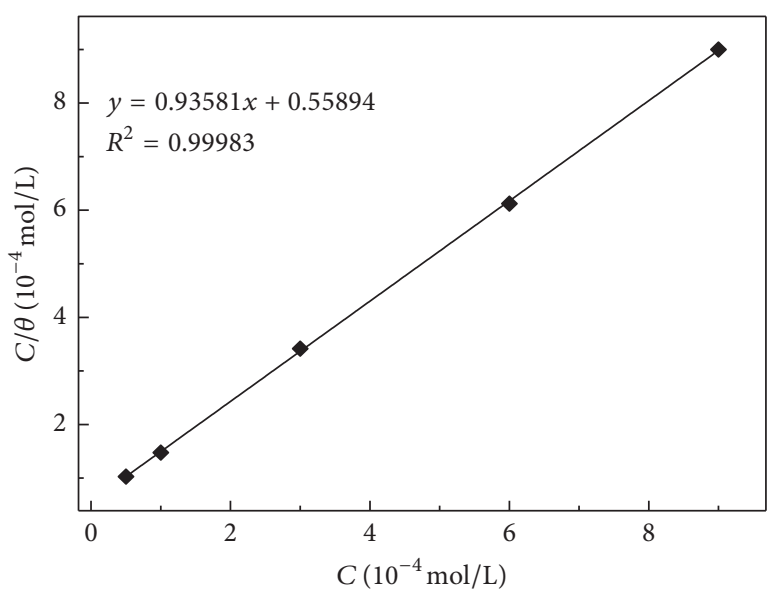

FIGURE 11: Langmuir fitting curve of synthetic product.

this case, the line has a slope of 0.936 and the correlation coefficient $\left(R^{2}\right)$ is 0.9998 . The linear relationship of $c / \theta$ versus $c$ shows that the synthetic product obeys Langmuir adsorption isotherm, which means that the synthetic product forms a dense monomolecular film on the surface of $2024 \mathrm{Al}$ $\mathrm{Cu}-\mathrm{Mg}$ alloy [37], effectively blocks corrosion ions near the metal surface, and slows down the corrosion of alloy surface.

The adsorption equilibrium constant $K$ could be calculated by using the fitted line above and $K=1.789 \times$ $10^{4} \mathrm{~L} / \mathrm{mol}$. Through (7), adsorption free energy $\Delta G_{\text {ads }}^{0}$ can be 
TABLE 3: Fitting parameters of equivalent circuit.

\begin{tabular}{lccccc}
\hline$C\left(10^{-4} \mathrm{~mol} \cdot \mathrm{L}^{-1}\right)$ & $R_{s}\left(\Omega \cdot \mathrm{cm}^{2}\right)$ & $R_{p}\left(\Omega \cdot \mathrm{cm}^{2}\right)$ & $Y_{0}\left(10^{-5} \Omega^{-1} \cdot \mathrm{cm}^{-2} \cdot \mathrm{s}^{-1}\right)$ & $n_{\mathrm{dl}}$ & $\mathrm{IE} \%$ \\
\hline 0 & 0.72 & 23.59 & 11.70 & 0.90 & 0.96 \\
0.5 & 0.51 & 32.71 & 10.60 & 0.92 & 27.9 \\
1 & 0.73 & 38.91 & 10.50 & 39.4 \\
3 & 0.82 & 77.05 & 8.46 & 0.87 & 69.4 \\
6 & 0.63 & 423.20 & 6.62 & 0.81 & 94.4 \\
9 & 0.98 & 436.90 & 6.00 & 0.96 \\
\hline
\end{tabular}

Note. C:concentration of synthetic product; $R_{s}$ :solution resistance; $R_{p}$ : polarization resistance; $Y_{0}$ :capacitive admittance of CPE capacitance; $n_{\mathrm{dl}}$ :empirical exponent of CPE capacitance [36]; IE: inhibition efficiency.

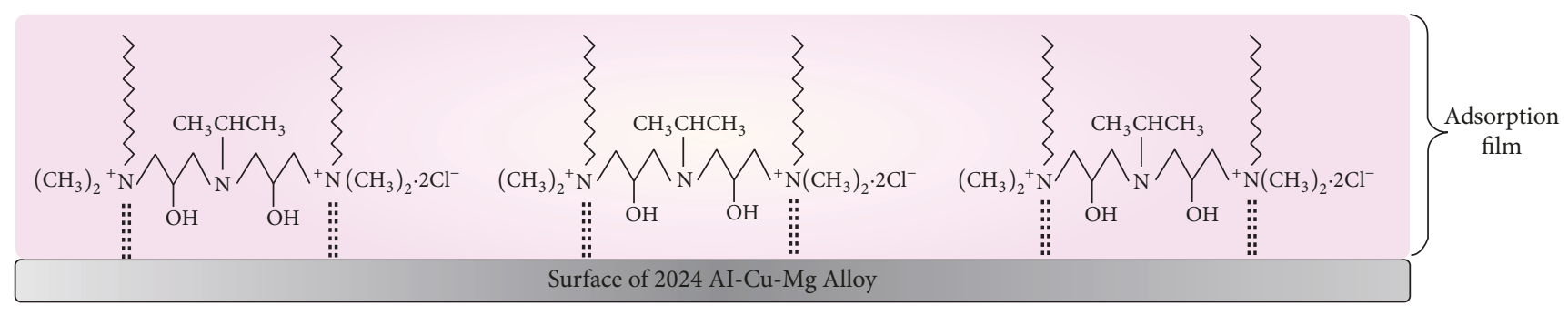

FIgURE 12: Physisorption between synthetic product and surface of $2024 \mathrm{Al}-\mathrm{Mg}-\mathrm{Cu}$ alloy.

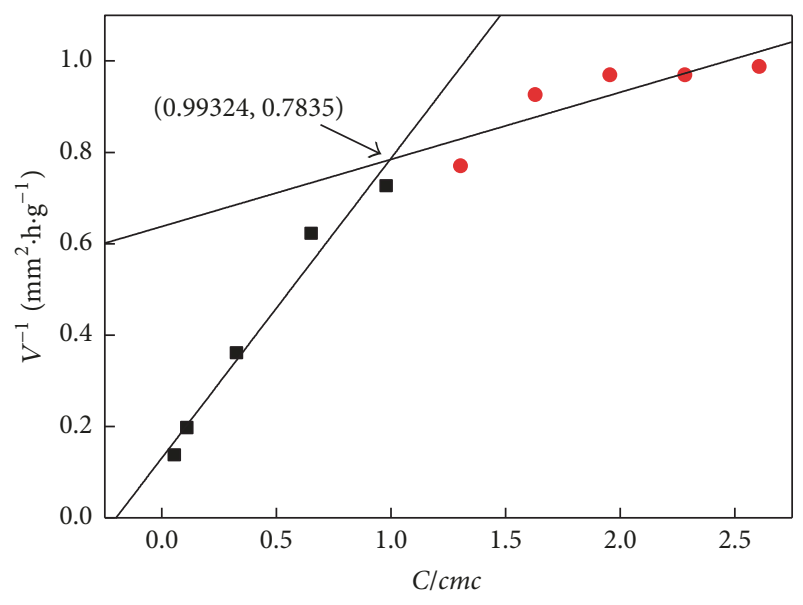

FIgURE 13: $V^{-1}-\mathrm{C} / \mathrm{cmc}$ curve of $2024 \mathrm{Al}-\mathrm{Cu}-\mathrm{Mg}$ alloy.

calculated and equals $-34.2 \mathrm{~kJ} / \mathrm{mol} . \Delta G_{\text {ads }}^{0}<0$ illustrates the adsorption process is spontaneous. A value of $\Delta G_{\mathrm{ads}}^{0}=$ $-40 \mathrm{~kJ} / \mathrm{mol}$ is usually adopted as the threshold value between chemisorption and physisorption [38]. Thus, it indicates that the adsorption of the synthetic product is more inclined to physisorption, where ammonium cations are attracted to the negative charge of the metal surface by electrostatic interaction and are adsorbed to the metal surface, as shown in Figure 12.

Fit again the weight loss test results through (6), fitted lines are shown in Figure 13, where the ratio of the concentration of synthetic product to the concentration of the critical micelle concentration $\mathrm{cmc}$ was set up as abscissa in order to explain the influence of $c m c$ on the corrosion rate.

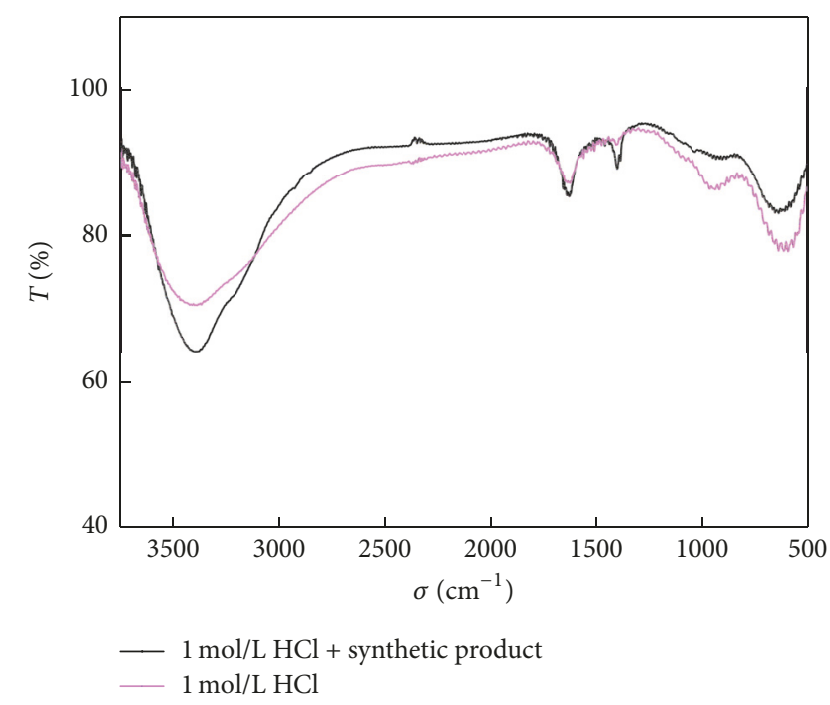

FIGURE 14: FTIR plots of corrosion products on metal surface in absence/presence of synthetic product.

It shows that the two fitted lines intersect when $\mathrm{C} / \mathrm{cmc}$ nearly equals 1 . Thus it can be deduced that when the concentration is higher than $c m c$, the adsorption behaviour of synthetic product on the metal surface changes.

3.4. Study on Corrosion Inhibition Mechanism. FTIR results of corrosion products on the surface of $2024 \mathrm{Al}-\mathrm{Cu}-\mathrm{Mg}$ alloy in $1 \mathrm{~mol} / \mathrm{L} \mathrm{HCl}$ solution with/without the synthetic product are shown in Figure 14. It can be analyzed that $3401 \mathrm{~cm}^{-1}$ is the vibration peak of $-\mathrm{OH}[31] ; 1626 \mathrm{~cm}^{-1}$ is the vibration peak of $\mathrm{AlCl}_{3}$ [39]; $1397 \mathrm{~cm}^{-1}$ and $946 \mathrm{~cm}^{-1}$ are the vibration peaks of $\mathrm{Al}_{2} \mathrm{O}_{3}$ and $\mathrm{MgO}[40] ; 618 \mathrm{~cm}^{-1}$ is the vibration peak 


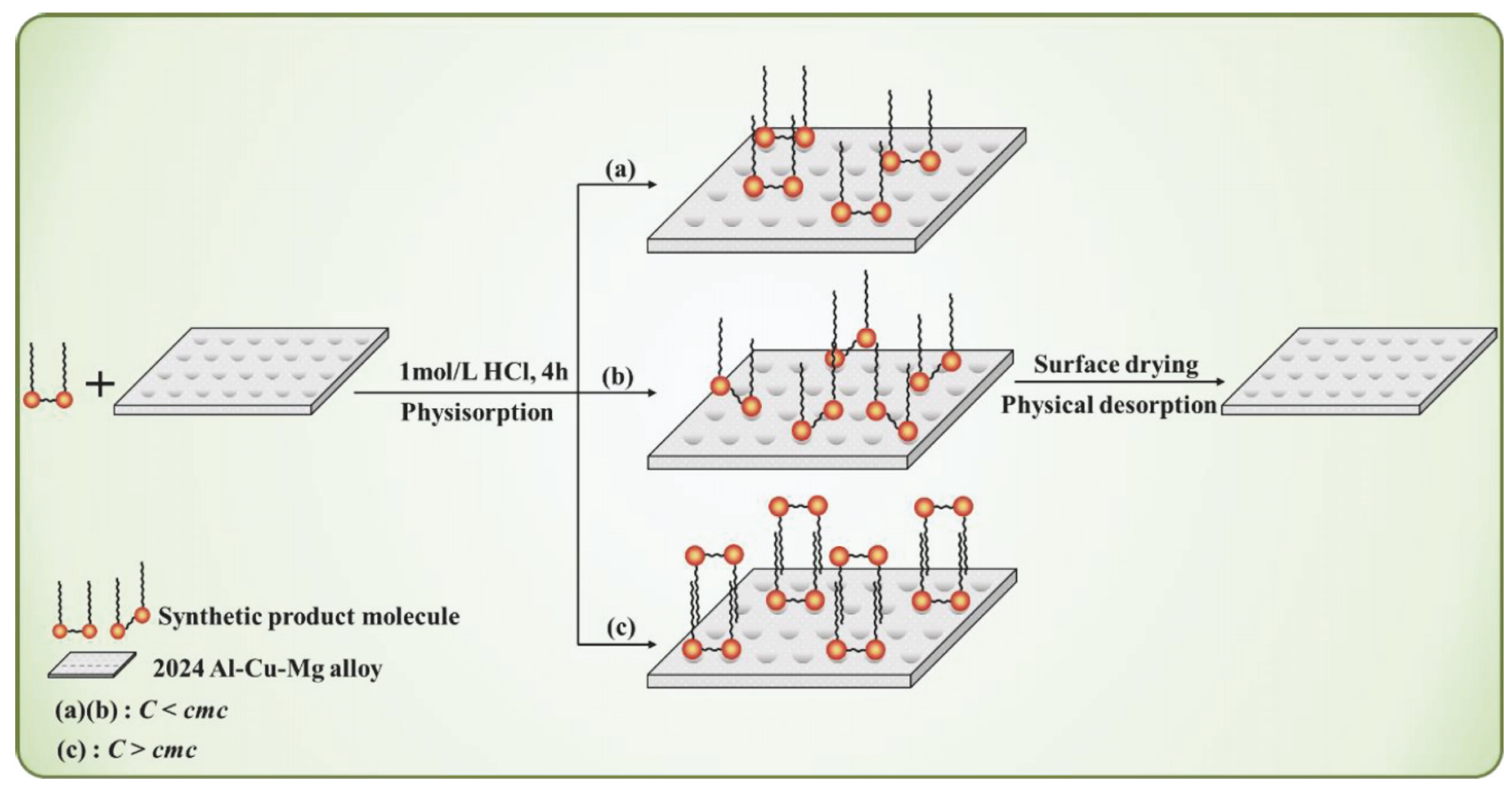

FIGURE 15: Adsorption principle of synthetic product on $2024 \mathrm{Al}-\mathrm{Cu}-\mathrm{Mg}$ alloy surface.

of $\mathrm{Cu}_{2} \mathrm{O}$ [39]. It can be indicated that no chemical bond appears or disappears by comparing two curves. As a result, it can be verified again that the adsorption of the synthetic product is physisorption.

In order to better explain the corrosion inhibition process and mechanism of the synthetic product on the surface of the alloy, the schematic diagram of the adsorption and desorption process is shown in Figure 15.

As seen in Figure 15, there might be two adsorption modes when the concentration of synthetic product is lower than $c m c$, as shown in (a) and (b). At low concentration, two hydrophilic groups are adsorbed on the metal surface; that is, each hydrophilic group occupies one adsorption site, as shown in (a); at higher concentration, one of two hydrophilic groups of gemini surfactant may be adsorbed on the metal surface adsorption site, while another cannot adsorb onto it, as shown in (b). In actual situation, the adsorption mode is more inclined to (a) (b) coexistence, and this adsorption mode still meets the Langmuir adsorption model, that is, monolayer adsorption.

When the concentration of synthetic product is higher than $c m c$, its adsorption on the metal surface is saturated. When keeping increasing the concentration, similar to the conventional surfactants which form micelles with inner hydrophobic groups and outer hydrophilic groups, the synthetic product molecules will form a bilayer adsorption film with hydrophobic groups at the middle and hydrophilic groups at both ends, as shown in (c). Therefore, the adsorption pattern does not accord with the monolayer adsorption film of Langmuir model assumed, which is a good explanation of the intersection point in Figure 13.

As a new environmental friendly inhibitor, the synthetic product has many advantages, one of which is its physisorption on metal surface. The synthetic product can be desorbed naturally without any extra process when the metal surface is dried. Hence, compared with chemical absorption/desorption, physical absorption/desorption is more concise, efficient, and environmentally friendly.

\section{Conclusions}

(1) Two-step method has been taken to synthesize a novel green inhibitor: bis[2-hydroxy-3-(dodecyldimethylammonio)propyl]-isopropylamine dichloride, FTIR, and ${ }^{1} \mathrm{H}$ NMR tests show that target product is the synthetic product.

(2) Critical micelle concentration $c m c$ of the synthetic product is $9.204 \times 10^{-4} \mathrm{~mol} / \mathrm{L}$; when the concentration is lower than $c m c$, inhibition efficiency of the synthetic product to $2024 \mathrm{Al}-\mathrm{Cu}-\mathrm{Mg}$ alloy increases monotonously and is up to $89.3 \%$ at $9 \times 10^{-4} \mathrm{~mol} / \mathrm{L}$; when it is higher than $\mathrm{cmc}$, inhibition efficiency of the synthetic product keeps basically unchanged.

(3) The Tafel polarization studies indicate that the synthetic product is of mixed anodic-cathodic type; each Nyquist plots is composed of a depressed capacitive arc in the high frequency zone; the electrochemical test results are consistent with the weight loss method.

(4) The adsorption type of synthetic product is physisorption. When the concentration is lower than $c m c$, the adsorption mode of the synthetic product conforms to the Langmuir adsorption model and forms a monolayer adsorption film on $2024 \mathrm{Al}-\mathrm{Cu}$ $\mathrm{Mg}$ alloy surface; when it is higher than $\mathrm{cmc}$, it forms 
bilayer adsorption film on metal surface and thus does not conform to the Langmuir adsorption model anymore.

\section{Conflicts of Interest}

The authors declare that they have no conflicts of interest.

\section{Acknowledgments}

This work was supported by supporting funds for discipline construction of Civil Aviation University of China under Grant no. 000032041110.

\section{References}

[1] B. Wang, Z. Y. Wang, G. W. Cao, Y. J. Liu, and W. Ke, "Localized corrosion of aluminum alloy 2024 exposed to salt lake atmospheric environment in western China," Acta Metallurgica Sinica, vol. 50, no. 1, pp. 49-56, 2014.

[2] H. M. Abd El-Lateef, M. A. Abo-Riya, and A. H. Tantawy, "Empirical and quantum chemical studies on the corrosion inhibition performance of some novel synthesized cationic gemini surfactants on carbon steel pipelines in acid pickling processes," Corrosion Science, vol. 108, pp. 94-110, 2016.

[3] M. A. Hegazy, A. A. Nazeer, and K. Shalabi, "Electrochemical studies on the inhibition behavior of copper corrosion in pickling acid using quaternary ammonium salts," Journal of Molecular Liquids, vol. 209, pp. 419-427, 2015.

[4] M. A. Hegazy, A. M. Badawi, S. S. Abd El Rehim, and W. M. Kamel, "Corrosion inhibition of carbon steel using novel N-(2(2-mercaptoacetoxy)ethyl)-N,N-dimethyl dodecan-1-aminium bromide during acid pickling," Corrosion Science, vol. 69, pp. 110-122, 2013.

[5] P. Singh, M. A. Quraishi, E. E. Ebenso, and C. B. Verma, "Ultrasound assisted synthesis of chalcones as green corrosion inhibitors for mild steel in 1M hydrochloric solution," International Journal of Electrochemical Science, vol. 9, no. 12, pp. 74467459, 2014.

[6] B. Gao and M. M. Sharma, "A new family of anionic surfactants for enhanced-oil-recovery applications," Society of Petroleum Engineers Journal, vol. 18, no. 5, pp. 829-840, 2013.

[7] R. Zana, "Dimeric and oligomeric surfactants. Behavior at interfaces and in aqueous solution: A review," Advances in Colloid and Interface Science, vol. 97, no. 1-3, pp. 205-253, 2002.

[8] M. S. Kamal, "A review of gemini surfactants: potential application in enhanced oil recovery," Journal of Surfactants \& Detergents, vol. 19, no. 2, pp. 223-236, 2016.

[9] W. Chen, B. Shao, Y. Liu, X. Li, M. Zheng, and L. Tian, "Application of gemini surfactants in the development of oil and gas fields," Journal of Yangtze University, vol. 13, no. 34, pp. 6670, 2016.

[10] J. Liu, D. Zhao S, and J. Li, Hu J J and Ren P B: Corrosion Protection, 2016.

[11] K. Cao, H. Y. Sun, and B. R. Hou, "Corrosion inhibition of gemini surfactant for copper in 3.5\% NaCl," Advanced Materials Research, vol. 936, pp. 1125-1131, 2014.

[12] J. Zhao, H. Duan, and R. Jiang, "Synergistic corrosion inhibition effect of quinoline quaternary ammonium salt and Gemini surfactant in $\mathrm{H} 2 \mathrm{~S}$ and $\mathrm{CO} 2$ saturated brine solution," Corrosion Science, vol. 91, pp. 108-119, 2015.
[13] A. Gautam and N. Kambo, Upadhyay S K and R P Singh: Colloids Surfaces A Physicochemical Engineering Aspects, pp. 195-202, 2008.

[14] E. Kang K, B. Lee M, H. A. Hwang, and J. C. Lim, "A novel cationic surfactant having two quaternary ammonium ions," Journal of Industrial and Engineering Chemistry, pp. 845-852, 2011.

[15] T.-S. Kim, T. Kida, Y. Nakatsuji, and I. Ikeda, "Preparation and properties of multiple ammonium salts quaternized by epichlorohydrin," Langmuir, vol. 12, no. 26, pp. 6304-6308, 1996.

[16] J. C. Lim, J. M. Park, J. P. Chan, and M. B. Lee, "Synthesis and surface active properties of a gemini-type surfactant linked by a quaternary ammonium group," Colloid \& Polymer Science, vol. 291, no. 4, pp. 855-866, 2013.

[17] C. J. Lim, K. E. Kang, M. J. Park, H. C. Kang, and B. M. and Lee, "Syntheses and surface active properties of cationic surfactants having multi ammonium and hydroxyl groups," Journal of Industrial \& Engineering Chemistry, vol. 18, no. 4, pp. 1406-1411, 2012.

[18] X. P. Liu, J. Feng, L. Zhang, and Q. T. Gong, "Synthesis and properties of a novel class of anionic gemini surfactants with polyoxyethylene spacers," Colloids \& Surfaces A Physicochemical Engineering Aspects, vol. 362, no. 1, pp. 39-46, 2010.

[19] X. M. Pei, Y. You, J. X. Zhao, Y. S. Deng, E. J. Li, and Z. X. Li, "Adsorption and aggregation of 2-hydroxyl-propanediyl- $\alpha, \omega$ bis(dimethyldodecyl ammonium bromide) in aqueous solution: Effect of intermolecular hydrogen-bonding," Journal of Colloid and Interface Science, vol. 351, no. 2, pp. 457-465, 2010.

[20] Z. Miao, F. Wang, D. Deng, Y. Zhang, X. Huo, and L. Wang, "Preparation of novel gemini quaternary ammonium salt cationic surfactant," Applied Mechanics and Materials, vol. 174177, pp. 1433-1436, 2012.

[21] F. H. Abdel-Salam and A. G. El-Said, "Synthesis and surface active properties of gemini cationic surfactants and interaction with anionic azo dye (AR52)," Journal of Surfactants and Detergents, vol. 14, no. 3, pp. 371-379, 2011.

[22] N. A. Negm and A. S. Mohamed, "Synthesis, characterization and biological activity of sugar-based gemini cationic amphiphiles," Journal of Surfactants and Detergents, vol. 11, no. 3, pp. 215-221, 2008.

[23] J. Z. Xu, M. Li, H. Xue, R. Li, and T. Ye, Corrosion Science \& Protection Technology, 2013.

[24] M. A. Hegazy, M. Abdallah, and H. Ahmed, "Novel cationic gemini surfactants as corrosion inhibitors for carbon steel pipelines," Corrosion Science, vol. 52, no. 9, pp. 2897-2904, 2010.

[25] D. Asefi, M. Arami, and N. M. Mahmoodi, "Electrochemical effect of cationic gemini surfactant and halide salts on corrosion inhibition of low carbon steel in acid medium," Corrosion Science, vol. 52, no. 3, pp. 794-800, 2010.

[26] D. Asefi, N. M. Mahmoodi, and M. Arami, "Effect of nonionic co-surfactants on corrosion inhibition effect of cationic Gemini surfactant," Colloids \& Surfaces A Physicochemical \& Engineering Aspects, vol. 355, no. 1-3, pp. 183-186, 2010.

[27] A. Adewuyi, A. Göpfert, and T. Wolff, "Succinyl amide Gemini surfactant from Adenopus breviflorus, seed oil: A potential corrosion inhibitor of mild steel in acidic medium," in Industrial Crops \& Products, vol. 52, pp. 439-449, Products, 1 edition, 2014.

[28] M. Mobin and S. Masroor, "Cationic gemini surfactants as novel corrosion inhibitor for mild steel in $1 \mathrm{M} \mathrm{HCl,"} \mathrm{International}$ Journal of Electrochemical Science, vol. 7, no. 8, pp. 6920-6940, 2012. 
[29] F. A. Ansari and M. A. Quraishi, "Inhibitive performance of gemini surfactants as corrosion inhibitors for mild steel in formic acid," Portugaliae Electrochimica Acta, vol. 28, no. 5, pp. 321-335, 2010.

[30] Z. Y. Wu, The research on the corrosion inhibition metal in acid medium by some gemini surfactants, Central South University, Changsha, China, 2011.

[31] B. H. Yan, P. Mei, Wu. X. M. L. Lai, and X. Yang, "Synthesis and rheological properties of multiple-quaternary ammonium surfactants," China Surfactant Detergent \& Cosmetics, vol. 6, pp. 301-305, 2015.

[32] R. G. Ge, L. Zhao, L. Lai, and P. Mei, "Synthesis of three based bis quaternary ammonium salt Gemini surfactant," Journal of Yangtze University (Nat Sci Edit), no. 2, pp. 17-20+405, 2010.

[33] T. G. Chi and Z. G. Cui, "Synthesis and properties of novel Gemini cationic surfactants (2) - multiple quaternary ammonium salts from dodecylamine and epichlorohydrin," China Surfactant Detergent Cosmetics, vol. 4, pp. 36-38, 2001.

[34] F. M. Menger and J. S. Keiper, "Gemini surfactants," Angewandte Chemie International Edition, vol. 39, no. 11, pp. 1906-1920, 2000.

[35] R. Atkin, V. S. J. Craig, E. J. Wanless, and S. Biggs, “Adsorption of 12-s-12 gemini surfactants at the silica-aqueous solution interface," The Journal of Physical Chemistry B, vol. 107, no. 13, pp. 2978-2985, 2003.

[36] Y. C. Qing, Z. W. Yang, J. Xian et al., "Corrosion behavior of Q235 steel under the interaction of alternating current and microorganisms," Acta Metallurgica Sinica, vol. 52, no. 9, pp. 1142-1152, 2016.

[37] X. K. He, B. L. Hou, Y. M. Jiang, C. Li, and L. Y. Wu, "Inhibition property and adsorption behavior of imidazole and 2-phenyl-2imidazoline on $\mathrm{Cu}$ in $\mathrm{H}_{2} \mathrm{SO}_{4}$ solution," Acta Metallurgica Sinica, vol. 49, no. 8, pp. 1017-1024, 2013.

[38] S. Taghi, Y. Alireza, and H. Mirghasem, "Inhibition behaviour of 2-butinel, 4diol and tartrate salt, and their synergistic effects on corrosion of AA3003 aluminium alloy in $0.5 \% \mathrm{NaCl}$ Solution," Journal of Materials Science \& Technology, vol. 24, no. 3, pp. 427432, 2008.

[39] J. J. Liu, "IR analysis of corrosion products on aluminum alloy in simulate island environments," Equipment Environmental Engineering, vol. 4, pp. 124-128, 2015.

[40] J. P. Lin, X. Wang, X. J. Yang, and H. L. Wan, "Effects of atmospheric pressure air plasma treatment on static strength of adhesive-bonded aluminum alloy," China Surface Engineering, vol. 3, pp. 110-121, 2017. 


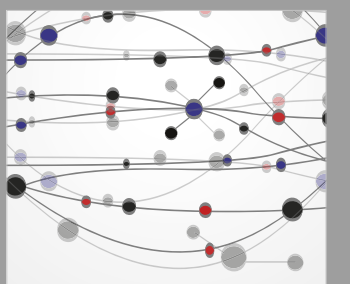

The Scientific World Journal
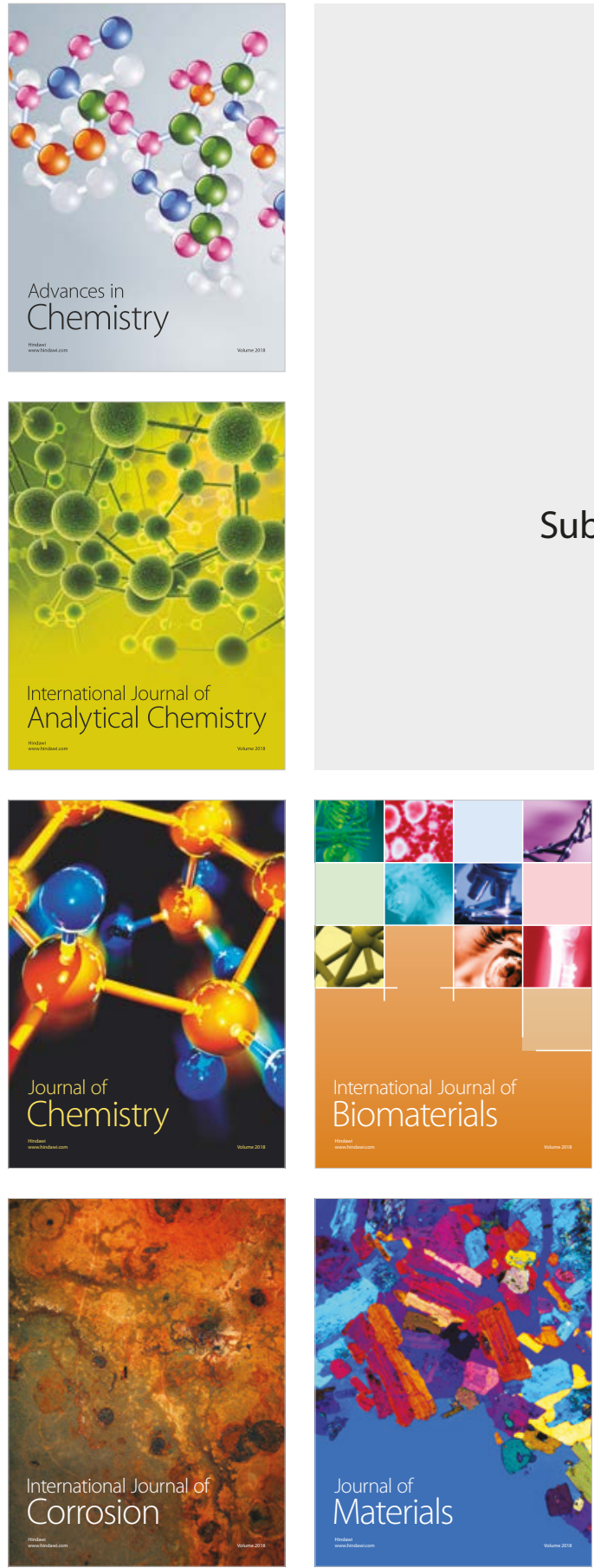

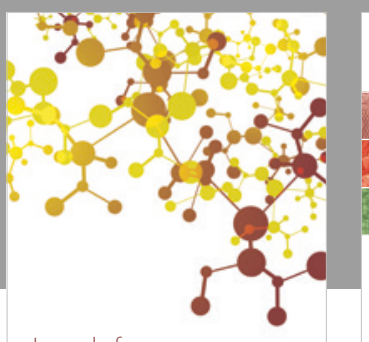

Journal of

Applied Chemistry
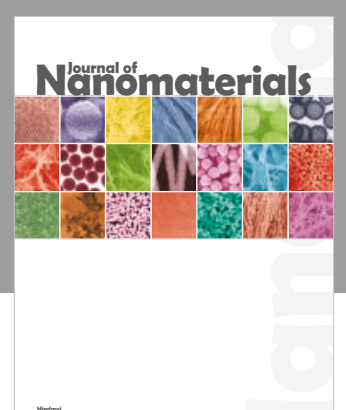

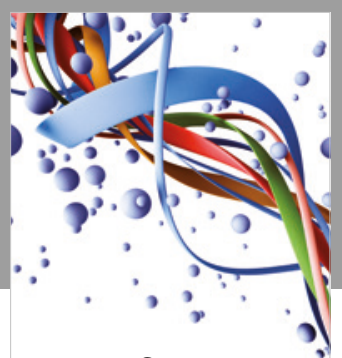

Scientifica

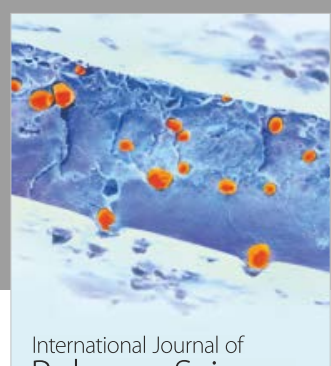

Polymer Science

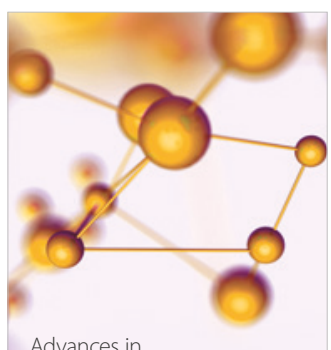

Physical Chemistry
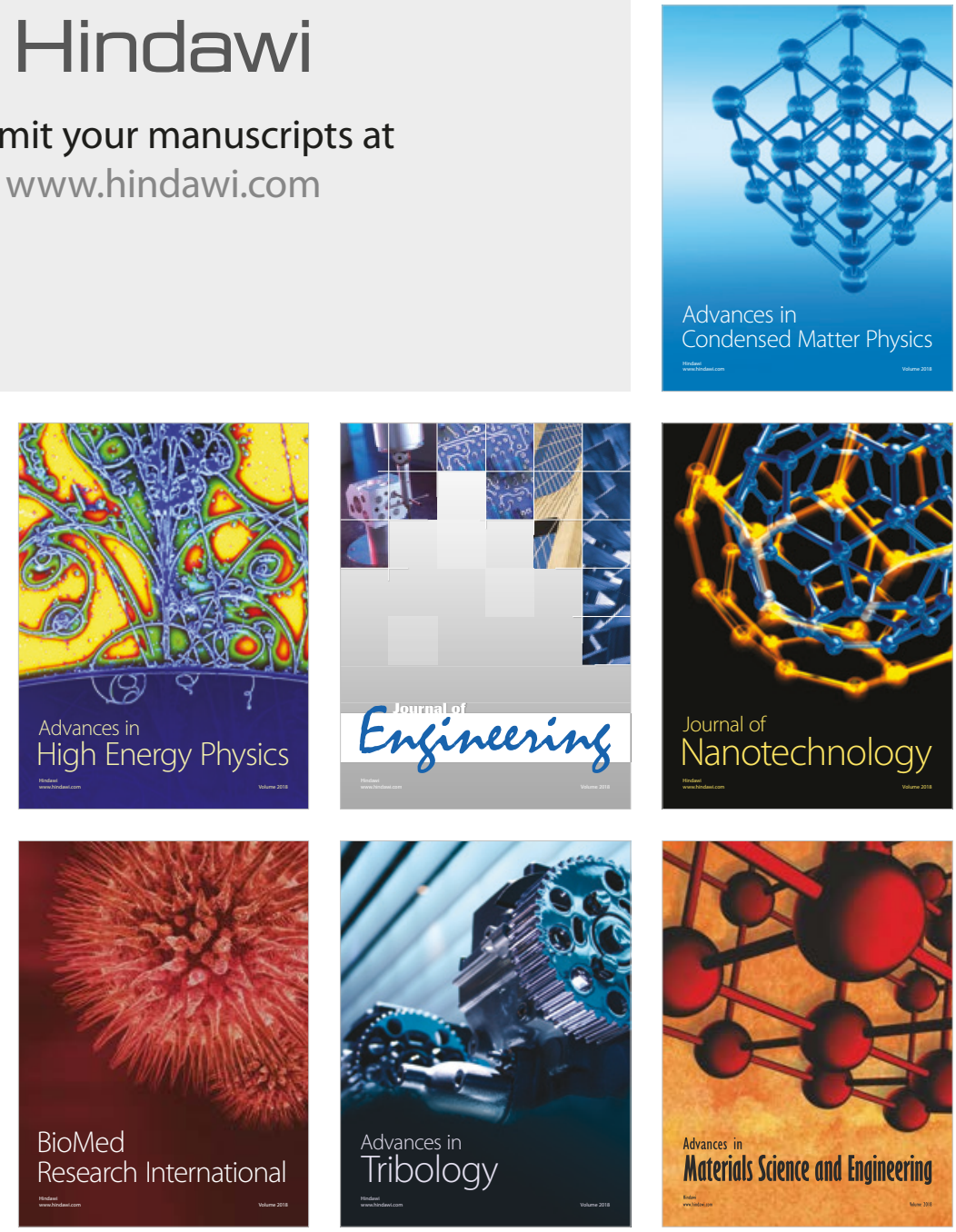